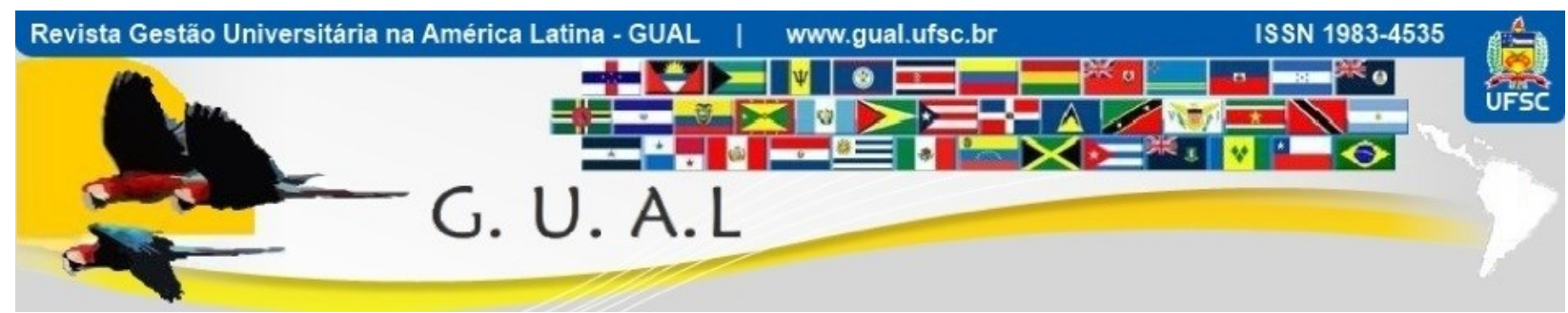

DOI: http://dx.doi.org/10.5007/1983-4535.2018v11n1p319

\title{
CENTROS DE PESQUISA EM TURISMO NO MERCOSUL: DISTRIBUIÇÃO, ÊNFASES E POSSÍVEIS INTERAÇÕES COMO FATOR DE DESENVOLVIMENTO
}

\section{DISTRIBUTION, EMPHASIS AND POSSIBLE INTERACTIONS AMONG TOURISM RESEARCH CENTRES IN MERCOSUL}

Thiago Duarte Pimentel, Doutor Universidade Federal de Juiz de Fora - UFJF thiago.pimentel@ufjf.edu.br

Fabíola Cristina Costa de Carvalho, Mestre Universidad Autonoma de Sinaloa - México fabiolacarvalho.tur@hotmail.com

Marcela Costa Bifano de Oliveira, Mestre Universidad de Guadalajara - Centro Universitário de la Costa - México marbifano@gmail.com

Recebido em 25/agosto/2015

Aprovado em 16/fevereiro/2017

Sistema de Avaliação: Double Blind Review

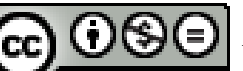

Esta obra está sob uma Licença Creative Commons Atribuição-Uso. 


\title{
RESUMO
}

O objetivo deste paper é apresentar um panorama da presença e das interações existentes entre Centros de Pesquisa em Turismo (CPT) entre os países do Mercosul, como pré-requisito de inovações no campo do turismo. Foi utilizado um método quantitativo e qualitativo de análise. Como resultado, verificou-se uma distribuição assimétrica dos CPTs entre os países, com ênfase inespecífica e sem relação uns com os outros. Neste contexto, o estágio de institucionalização da produção de conhecimento em turismo, como condição prévia para o seu desenvolvimento, ainda é incipiente.

Palavras-chave: Turismo. Oferta Educativa. Centro de Pesquisa. Conhecimento.

\begin{abstract}
The aim of this paper is to presente an overview about the existence and the likely interactions of Tourism Research Centres (TRC) among the Mercosul countries, as a prerequisite of innovations in tourism field. It was used a quantitative and qualitative method of analysis. As a result it was found an asymmetrical distribution of TRC between the countries, with nonspecific emphasis and no relation to each other. In this regard the institutionalization stage of knowledge production in tourism, as a precondition of its development, is still incipient.
\end{abstract}

Keywords: Tourism. Educactional Offer. Research Centre. Knowledge. 


\section{INTRODUÇÃO}

A produção de conhecimento contribui muito para um aperfeiçoamento de técnicas que podem ser aplicadas na realidade, contribuindo para o desenvolvimento. Para Leniado e Santos (2012) o papel do conhecimento é construtivo pois possui ilimitadas possibilidades no avanço da ciência e da cultura de uma nação ou conjunto de nações empenhadas em projetos conjuntos. As inovações tecnológicas e sociais são fatores indispensáveis para o posicionamento dos países em âmbito global. Por um lado, a produção técnico-científica corresponde a uma exigência do sistema de produção capitalista, mas, por outro, incentiva a discussão para debates e produção de práticas mais democráticas (LANIADO; SANTOS, 2012).

A produção de conhecimento, em geral, é feita por centros de investigação (pesquisa) ou universidades. Os centros de pesquisa são organismos responsáveis por fazer pesquisas e descobrir novas técnicas, inovando em estratégias e fazendo comparações da teoria com a prática. São responsáveis pela geração de novas tecnologias necessárias para a sociedade, influenciando diretamente em seu desenvolvimento.

A interação entre centros de pesquisa pode contribuir para o aumento da geração dessas tecnologias, em questão de quantidade e principalmente de qualidade dos estudos e técnicas adquiridos. Ou seja, a (maior ou menor) interação entre os centros de pesquisa não só retroalimenta a produção de conhecimento como também potencializa.

Nesse sentido, visando estabelecer um panorama a respeito dos centros de pesquisa em turismo/CPT e suas possíveis interações, no âmbito do Mercosul, é que se insere esta investigação - ainda em curso - cujos resultados preliminares, realizados a partir de um recorte do estudo mais amplo, são apresentados a seguir. Para tanto, neste artigo visa-se: (1) identificar e quantificar os CPT existentes nos países do Mercado Comum do Sul / Mercosul; (2) especificar qual a área de conhecimento de cada um; (3) comparar as ênfases de estudos de cada centro de pesquisa e apontar possíveis integrações entre eles, e por fim (4) identificar a existência de relações formais entre esses centros e os possíveis resultados dessas interações, como, por exemplo, os projetos de pesquisa em comum e intervenções já realizadas em alguma região.

O Mercosul é um cenário importante para a investigação sobre produção de conhecimento em turismo, pois, à exceção do México , é a região que mais tem produzido pesquisas em turismo na América Latina, tendo recentemente promovido a ligação de redes 
sociais (de pesquisadores) e organizacionais (de instituições) entre as academias cientificas de turismo de vários países, como se verifica em eventos de grande porte (cf. CLAIT, 2012; ANPTUR, 2013).

Além de seus objetivos comercias - a livre circulação de bens, serviços e fatores produtivos, do estabelecimento de uma Tarifa Externa Comum (TEC), adoção de uma política comercial comum (MERCOSUL, 2013) - o Mercosul também estabelece a uma ampla plataforma para a discussão e elaboração de ações conjuntas, sobre diferentes temáticas como educação, cultura, meio ambiente, entre outros, incluindo o turismo (LANIADO; SANTOS, 2012). Esses laços formais facilitam a integração dos países inclusive na área da produção científica, as universidades e centros de pesquisa podem se filiar com a finalidade de promover o turismo na região, desenvolvendo técnicas e saberes específicos do setor.

Nesse sentido, considerando este rico contexto e o oportuno momento de produção de conhecimento na América do Sul, em particular, no Mercosul (FREY, 2014; NASSI-CALÒ, 2014), é que se justifica a realização deste estudo com vistas a parcerias entre os CPT desses países, já que a constituição de uma rede de CPT poderia distribuir informações e trocar experiências do setor turístico, visando contribuir para o bem estar econômico e social dos países envolvidos na rede de CPT. Além disso, conhecimentos poderiam ser aplicados empiricamente contribuindo assim para o aumento na tendência de crescimento no fluxo turístico da América do Sul, já que apesar desse crescimento a atividade de pesquisa ainda carece de melhores investimentos e um conhecimento mais aprofundado dessa realidade pode nos ajudar a direcionar a construção de uma agenda institucional de pesquisas bem como a orientar os investimentos e às realizações nesta área.

Para organizar a exposição das ideias, além desta introdução, este artigo é constituído por cinco partes. Primeiramente, abordamos a importância das relações entre desenvolvimento e turismo e como o turismo pode contribuir para a geração de desenvolvimento com foco na produção de conhecimento científico, teórico e aplicado, via centros de pesquisa e suas parcerias e redes visando ampliação do conhecimento e sua democratização. Na sequência, descrevemos o método de pesquisa utilizado quantiqualitativa, com espaço para a análise estatística descritiva e a elaboração de um protocolo de pesquisa próprio para dar conta da diversidade e amplitude dos dados recolhidos. Em seguida, evidenciamos, a partir da análise das áreas especificas de pesquisa, a malha de centros de pesquisa existente no Mercosul bem como as possíveis interações entre eles, no 
sentido de aprimorar técnicas em vista ao desenvolvimento turístico regional desses países. Por fim, apontamos as considerações a que este estudo nos permitiu chegar.

\section{DESENVOLVIMENTO - TURISMO - DESENVOLVIMENTO?}

\subsection{DESENVOLVIMENTO - TURISMO}

Inversamente ao senso comum que prega (acriticamente) o turismo como fonte de desenvolvimento, alguns autores (MONTEJANO; 2001; OURIQUES, 2008; PIMENTEL, PIMENTEL; 2012; 2013) têm evidenciado que esta relação não é tão simples e linear, apontando, desde uma perspectiva macrossocial, que o grau de desenvolvimento entre os países afeta a existência ou não de turismo e o modo (possibilidade) de o turismo ser revertido em desenvolvimento.

Montejano (2001), por exemplo, percebeu que os países desenvolvidos (Estados Unidos, Inglaterra, Alemanha, Japão, etc.) são os principais emissores de turistas mundiais, e também apresentam o maior gasto diário médio por viagem, ao mesmo tempo, possuem uma alta demanda por turismo interno, além de apresentarem um elevado receptivo de turismo internacional. Quanto aos países de desenvolvimento intermediário (Grécia, Turquia, Croácia, etc.) são países predominantemente receptores, e contam também com o mercado interno de turismo aquecido. Já os países em desenvolvimento, ou subdesenvolvidos, em sua análise, são predominantemente receptores.

Sinteticamente, poderia se elaborar três grupos (MONTEJANO, 2001):

- O primeiro seria composto por aqueles países pequenos e especializados (Bahamas, Costa Rica, República Dominicana, etc.);

- No segundo se incluem aqueles países pouco especializados, porém receptivos (China, Malásia, México);

- O terceiro é integrado por países de receptivo reduzido (Bolívia, Equador, Nicarágua, Paraguai e Brasil);

Ainda, Montejano (2001) analisa o caso dos países de economia planificada, principalmente os países do leste europeu, e observa que eles eram receptores e emissores. Diferiam-se dos países desenvolvidos, pois apesar de apresentarem emissão alta, eram emissores principalmente para os próprios países do leste europeu, e, além disso, registravam baixo gasto médio por viagem. 
Ouriques (2008), por sua vez, observa que nos últimos 50 anos os países subdesenvolvidos têm empreendido grande esforço (isenções, incentivos, doações de terra, etc.) para mudar esse cenário, contudo, ainda não foi suficiente para alterar a estrutura mundial da economia turística. $\mathrm{O}$ autor analisa alguns números apresentados pela Organização Mundial do Turismo (OMT), relativos ao período de 1990 - 2004:

Tabela 1: Chegada de turistas por região do mundo

\begin{tabular}{|l|l|l|l|l|}
\hline Região & $\mathbf{1 9 9 0}$ & $\mathbf{1 9 9 5}$ & $\mathbf{2 0 0 0}$ & $\mathbf{2 0 0 4}$ \\
\hline Europa & 60,45 & 58,24 & 57,55 & 55,38 \\
\hline EUA + Canadá & 12,42 & 11,17 & 10,30 & 8,51 \\
\hline México + América Central & 4,35 & 4,22 & 3,63 & 3,44 \\
\hline Caribe & 2,59 & 2,59 & 2,48 & 2,36 \\
\hline América do Sul & 1,76 & 2,17 & 2,21 & 2,09 \\
\hline Ásia + Oceania & 12,77 & 15,30 & 16,19 & 18,98 \\
\hline África & 3,47 & 3,78 & 4,11 & 4,50 \\
\hline Oriente Médio & 2,19 & 2,53 & 3,52 & 4,73 \\
\hline Total & $\mathbf{1 0 0 , 0 0}$ & $\mathbf{1 0 0 , 0 0}$ & $\mathbf{1 0 0 , 0 0}$ & $\mathbf{1 0 0 , 0 0}$ \\
\hline
\end{tabular}

Fonte: Ouriques (2008, p.7)

Como é possível notar, a Europa concentra a maior parte do fluxo mundial de turistas (55,38\%), seguida pelo conjunto composto pelos continentes asiático e Oceania, que apresenta considerável aumento do número de turistas, o que se deve, principalmente, pelo crescimento do turismo na China, crescimento este ocasionado, segundo Ouriques, de um lado, pela abertura política e econômica promovida pelo país ao longo dos anos 1980, e de outro, a baixa valorização da moeda chinesa, que favorece o câmbio para os turistas. Europa, Estados Unidos e Canadá concentraram, em 2004, 63,89\% do fluxo turístico mundial.

Como consequência dessa distribuição do fluxo internacional de turistas, a distribuição da receita turística internacional também é desequilibrada entre países desenvolvidos e subdesenvolvidos.

Tabela 2: Receita turística internacional por região de destino (em\%)

\begin{tabular}{|l|l|l|l|l|}
\hline Região & $\mathbf{1 9 9 0}$ & $\mathbf{1 9 9 5}$ & $\mathbf{2 0 0 0}$ & $\mathbf{2 0 0 4}$ \\
\hline Europa & 52,89 & 51,66 & 48,28 & 51,01 \\
\hline EUA + Canadá & 18,83 & 17,74 & 19,70 & 16,08 \\
\hline México + América Central & 2,37 & 1,93 & 2,40 & 2,58 \\
\hline Caribe & 3,23 & 2,98 & 3,56 & 2,99 \\
\hline América do Sul & 1,83 & 1,75 & 1,91 & 1,84 \\
\hline Ásia + Oceania & 17,20 & 19,65 & 18,73 & 20,62 \\
\hline África & 2,37 & 2,07 & 2,18 & 3,15 \\
\hline Oriente Médio & 1,90 & 2,66 & 3,65 & 4,04 \\
\hline Total & $\mathbf{1 0 0 , 0 0}$ & $\mathbf{1 0 0 , 0 0}$ & $\mathbf{1 0 0 , 0 0}$ & $\mathbf{1 0 0 , 0 0}$ \\
\hline
\end{tabular}

Fonte: Ouriques (2008, p.9). 
Como se vê na tabela 2, a Europa, os Estados Unidos e o Canadá, juntos, concentravam 71,16\% das receitas mundiais em 1990, passando em 2004 a 64,96\%. Apesar dessa redução, é ainda inegável concentração das riquezas do setor nesses países.

Sendo assim, o autor questiona, inclusive, o recorrente argumento de que o turismo, em si, leva ao desenvolvimento. Para ele, o desenvolvimento econômico parece, ao contrário, proporcionar as condições para que o turismo se desenvolva.

Para reforçar este argumento, o autor ainda menciona que, na periferia do capitalismo, o turismo não tem se apresentado como uma base para o desenvolvimento, e "nos casos mais extremos, o turismo internacional impôs aos países emergentes uma forma de desenvolvimento de tipo neocolonial, isto é, retira poder dos níveis local e regional e o concentra nas mãos das companhias multinacionais" (OURIQUES, 2008, p.12).

Durante o século XX o processo de desenvolvimento esteve relacionado à industrialização, através do crescimento das cidades e da exploração dos recursos naturais. Contudo no presente momento essa visão é ultrapassada. Assim no século XXI o desenvolvimento passou a ser atrelado a novas perspectivas de melhorias associados à qualidade de vida. Segundo Tomazzoni, Patrucco e Buhler (2014) toda e qualquer proposta de crescimento econômico somente tem razão, fundamentado em sentido de priorizar a inclusão social.

Dessa forma, segundo Oliveira (2002) o desenvolvimento deve resultar do crescimento econômico acompanhado de melhoria na qualidade de vida, ou seja, deve melhorar os indicadores de bem-estar econômico e social (pobreza, desemprego, saúde, educação, moradia e alimentação). A industrialização consegue aumentar a estrutura produtiva, mas, entretanto, aumenta as disparidades entre o crescimento econômico e o desenvolvimento, diminuindo a qualidade de vida da população (OLIVEIRA, 2002).

O desenvolvimento tanto econômico quanto social é de grande importância para a sociedade. $\mathrm{O}$ aumento da produção e da produtividade do sistema econômico são elementos essenciais para aumentar o bem-estar da população, obtendo assim um maior desenvolvimento humano. Ou seja, o que importa, é como os frutos do progresso, da industrialização, do crescimento econômico são distribuídos para a população de modo a melhorar a vida de todos (OLIVEIRA, 2002). 


\subsection{TURISMO - DESENVOLVIMENTO}

O turismo se tornou uma opção viável para os países em desenvolvimento. A renda obtida com o turismo escorre para diferentes grupos da sociedade, ou seja, o consumo de viagens e serviços de lazer, tem uma característica multisetorial do turismo, proporcionando o desenvolvimento de vários segmentos produtivos (TOMAZZONI, PATRUCCO \& BUHLER, 2014).

Dessa forma, o turismo pode beneficiar diretamente grupos mais pobres, através de oportunidades de empregos para a população local em empresas de turismo, que oferecem bens e serviços aos visitantes, reduzindo assim os níveis de pobreza (OMT, 2014) e incluindo a sociedade no processo de desenvolvimento.

O desenvolvimento do turismo pode contribuir para a diminuição da pobreza (geração de empregos) e para o aumento da infraestrutura em geral (estradas, saneamento, comunicação, abastecimento de água, etc), contribuindo para o bem-estar da população local. Mas, para tanto, é necessário um planejamento coerente e responsável no destino turístico para que não haja o esgotamento desses recursos e para que a atividade realmente possa proporcionar benefícios e qualidade de vida.

Todavia, é necessário que se produza conhecimento mais preciso e seguro que possa orientar a intervenção na realidade. Para isso, os países do Mercosul podem aproveitar a aliança existente do bloco econômico, para juntos transformarem a atividade turística como parceira no crescimento e desenvolvimento de seus países.

Em 2013 o turismo obteve um crescimento de 4\% na América Central e de 2\% na América do Sul, apresentando uma desaceleração em comparação a 2012 (OMT, 2014). Esse dado demonstra a incapacidade dos países do sul em desenvolverem o turismo na região, o que se torna curioso já que o turismo é um mecanismo de importante influência para os países em desenvolvimento, podendo contribuir de forma significativa para o crescimento socioeconômico.

O turismo está sempre à procura de desenvolvimento. Com a chegada dos turistas o sistema de produção é acelerado gerando um crescimento econômico para as cidades e regiões. Portanto o turismo deve chegar nas cidades como forma de beneficiar a população local e não de prejudicar. Ou seja, pode haver desenvolvimento, mas as características daquela cidade ou região devem ser preservadas, como por exemplo, as características 


\section{CENTROS DE PESQUISA EM TURISMO NO MERCOSUL: DISTRIBUIÇÃO, ÊNFASES E POSSÍVEIS \\ INTERACCÕES COMO FATOR DE DESENVOLVIMENTO \\ DOI: http://dx.doi.org/10.5007/1983-4535.2018v11n1p319}

culturais, gastronômicas e arquitetônicas, e uma maior circulação de capital contribui para o desenvolvimento de uma forma geral.

A interação entre CPT podem proporcionar esse desenvolvimento mais humano. Os estudos e técnicas adquiridos e disseminados uns para os outros facilita a abordagem e a criação de modelos de desenvolvimento que sejam capazes de promover o desenvolvimento socioeconômico. Através de estudos e pesquisas, que se é possível interferir na realidade proporcionando melhorias para a população.

\section{CENTROS DE PESQUISA EM TURISMO (CPT) E SUAS POSSÍVEIS FORMAS DE INTERAÇÃO}

\subsection{CENTROS DE PESQUISA EM TURISMO}

A produção de conhecimento contribui muito para um aperfeiçoamento de técnicas que podem ser aplicadas na realidade, contribuindo para o desenvolvimento. Os centros de pesquisa são organismos responsáveis por fazer pesquisas e descobrir novas técnicas, inovando em estratégias e fazendo comparações da teoria com a prática. São responsáveis pela geração de novas tecnologias necessárias para a sociedade, influenciando diretamente em seu desenvolvimento. A interação entre centros de pesquisa pode contribuir para o aumento da geração dessas tecnologias, em questão de quantidade e principalmente de qualidade dos estudos e técnicas adquiridos.

Os CPT nas universidades ajudam a promover o crescimento da indústria turística, através da formação acadêmica ou de pesquisas que busquem estudar as áreas importantes para o desenvolvimento da atividade em questão. Resumidamente, os CPT têm como principal objetivo fornecer dados para que políticas de desenvolvimento em turismo possam ser geradas a partir de um fundamento. Os dados criados por estes centros partem de estudos multidisciplinares, levando em conta diversos aspectos, desde ambientais a socioculturais para promover discussões acerca dos avanços e desenvolvimento do turismo, buscando também solucionar os problemas encontrados pela indústria do turismo (CHRISTIAN, s/d).

\subsection{FORMAS PONTUAIS: PARCERIA E COOPERAÇÃO}

As organizações responsáveis pela produção de conhecimento ou pesquisa e conhecimento (P\&D) - geralmente centros de pesquisa, públicos ou privados, e as universidades - podem interagir de diferentes maneiras e com diferentes propósitos, sejam 
comerciais, filantrópicos ou de desenvolvimento social. Para isso, em geral, torna-se necessário que essas organizações especializadas nesta função (produção de conhecimento) interajam com outras que medeiam a difusão do conhecimento gerado para uma ampla parte da população.

A parceria e coordenação são mecanismos de descentralização e de compartilhamento de técnicas e informações que ajudam na prática do desenvolvimento econômico e social. As iniciativas de parcerias e cooperação veem se transformando em grandes mecanismos na economia atual, e se encontram nos âmbitos das relações interorganizacional e intersetorial. Os atores envolvidos ganham vantagens a nível econômico e social, através da redução de custos a longo prazo, aumento da eficiência, equidade e harmonia entre os atores, proporcionando uma maior rapidez nas tomadas de decisões (AMARAL, 2014).

A cooperação envolve a comunicação, a troca de informação, o ajustamento de atividades, e trocas de recursos para atingir metas e objetivos. A divisão do trabalho é seu ponto forte, sendo que cada ator desenvolve suas atividades de forma independente, apesar de haver coordenação entre eles (AMARAL, 2014).

Para Tuomela (2010), cooperação significa trabalhar em conjunto para o mesmo fim coletivo e agir em conjunto para atingir esse objetivo, no sentido de que os envolvidos não possuem capacidade para resolver os problemas sozinhos. Já a parceria apresenta aspectos como a partilha de recursos, o trabalho em conjunto a existência de interações frequentes. Estas podem ser altamente estruturadas por acordos legais vinculativos (relações de cooperações formal), ou por acordos verbais não formalizados (relações de cooperação informal) entre os atores envolvidos (SELIN; CHAVEZ, 1995).

\subsection{FORMAS PERENES: ESTRUTURA EM REDE}

As redes podem ser compreendidas como formas independentes de coordenação de interações. A cooperação é o aspecto central da rede, é baseada em confiança entre os atores autônomos e interdependentes. Esses trabalham em conjunto, levando em conta o interesse de seus parceiros, pois essa forma de coordenação é o caminho mais fácil para cada um atingir seus objetivos particulares (FREY, 2003).

O estudo das redes sociais pode ter uma perspectiva abrangente, dependendo do tipo de estudo que se pretende identificar. As redes sociais podem ter seu foco em diferentes tipos de relações, como, por exemplo, as relações dos atores de uma mesma organização, ou de 
interações de organizações diferentes, ou somente de organizações do setor público ou privado (KNUPP, 2014).

Essa relação entre os atores sociais se dá em contextos e campos variados, imersos em setores específicos ou não, em regiões delimitadas, próximas ou distantes. A partir de uma análise sobre as redes é possível quantificar e qualificar as relações entre os atores como formais/informais, fortes/fracos, cooperação/competição, e dessa forma compreender as interdependências e as assimetrias de poder existentes nas ações coletivas (KNUPP, 2014).

A análise interorganizacional identifica inter-relações de organismos distintos que cooperam de modo formal ou informal em prol de um projeto ou objetivo comum. As organizações agem no interior de um sistema de relações concretas em permanente desenvolvimento, e essa relação, além de proporcionar força, proporciona também conteúdo (GRANOVETTER, 1985).

Essa forma de estrutura da rede se torna atraente para os CPT, pois a junção de várias técnicas e experiências diferentes produzidas por cada um deles ou por eles conjuntamente, facilita a incorporação de mecanismos mais elaborados. O que facilita, já que otimiza tempo e recursos, dando mais qualidade nas técnicas e discussões.

Essas interações que formam a rede podem proporcionar uma maior qualidade e quantidade do conteúdo produzido pelos mesmos, podendo promover o desenvolvimento nessas regiões, gerando benefícios e qualidade de vida para as populações. É nesse sentido que é proposto uma interação entre os CPT no Mercosul.

\section{METODOLOGIA}

Apresentamos aqui um recorte de uma pesquisa - inserida num contexto mais amplo que mapeou as universidades de 23 países selecionados com o objetivo de traçar um panorama da oferta educacional superior e da produção de conhecimento em turismo em âmbito mundial (PIMENTEL, 2013).

Nesse estudo utilizou-se uma metodologia quanti-qualitativa, que nos permitiu um estudo mais completo em relação a realidade estudada, dessa forma é possível analisar em números o nosso panorama da quantidade de CPT e em seguida interpretar esses dados de acordo com as suas respectivas categorias (VEAL, 2011), sendo possível fazer um estudo das prováveis relações entre os CPT do Mercosul com vistas ao desenvolvimento turístico na América do Sul. 


\section{CENTROS DE PESQUISA EM TURISMO NO MERCOSUL: DISTRIBUIÇÃO, ÊNFASES E POSSÍVEIS \\ INTERAÇÕES COMO FATOR DE DESENVOLVIMENTO \\ DOI: http://dx.doi.org/10.5007/1983-4535.2018v11n1p319}

Esta pesquisa, de cunho exploratório e descritivo, seguida pelo método survey, seleciona amostragem e aplica técnicas quantitativas de coleta de dados, que posteriormente são descritos e estabelecida as relações existentes entre eles (GIL, 1995).

Foram investigadas 2834 instituições de ensino superior (IES) distribuídas da seguinte forma:129 na Argentina; 2429 no Brasil, 67 no Paraguai, 39 no Uruguai e 170 na Venezuela. Em todos os casos recorreu-se a um censo das IES declaradas existentes nestes países, disponível pelo Ministério da Educação, ou entidade governamental de nível nacional similar, para uma identificação inicial. Posteriormente, complementou-se o levantamento através de uma busca em fontes secundárias e também pelo conhecimento prévio sobre as instituições de ensino existente nos países investigados.

Posteriormente ao levantamento do número de universidades de cada país, buscou-se o endereço eletrônico de cada instituição de ensino, com vistas a verificar quantos e quais cursos de turismo são oferecidos no país, em que departamento ou unidade estava vinculado e se possui centros de pesquisa, entre outras categorias.

A partir dos dados obtidos via o endereço eletrônico de cada universidade de cada país, foi possível fazer uma análise de conteúdo quantificando os CPT existentes e os selecionando em suas respectivas áreas do conhecimento. Para tanto elaborou-se um protocolo de pesquisa (PIMENTEL; PAULA, 2014) por meio do qual foram coletadas, ordenadas e classificadas as universidades e seus centros de pesquisa, segundo categorias temáticas pré-estipuladas com base em estudos anteriores (PIMENTEL, 2013).

De posse desses dados foi feito um corte nos cinco países do Mercosul para identificar os dados relevantes para essa análise. Assim, com base na identificação dos CPT e na descrição de suas características foi possível esboçar as redes e integrações viáveis entre esses centros, facilitando a visualização das discrepâncias entre a quantidade de centros e suas respectivas ênfases de estudos entre os países selecionados.

Argumenta-se que a integração de centros de pesquisa pode gerar dados, informações e tecnologias relevantes para a indústria do turismo contribuindo para o desenvolvimento turístico na região, não somente no sentido econômico, mas de desenvolvimento humano, com participação democrática, trazendo benefícios para as sociedades envolvidas no sentido de um maior bem estar social.

A pesquisa documental, feita através dos sites oficiais das universidades, obteve algumas limitações. Como o procedimento de levantamento dos dados foi feito via internet as 
universidades encontradas foram aquelas que estavam com seus endereços eletrônicos disponíveis e ativos na rede. Todavia houve casos em que mesmo sendo identificada a instituição o sitio eletrônico não estava disponível, ou mesmo é possível que alguma instituição não tenha sido identificada. Como decorrência da metodologia utilizada também os dados encontrados sobre cada universidade foram somente aqueles que estavam disponíveis em seus sites oficiais. Dessa forma pode haver alguma incompatibilidade com a realidade, no sentido de que as atualizações das informações podem não ter sido realizadas. No caso do Brasil, diante da impossibilidade de se recuperar os dados de todas as IES recorreu-se a uma amostragem aleatória simples.

\section{ANÁLISE}

\subsection{LÓCUS DE PESQUISA: MERCOSUL}

O Mercado Comum do Sul (Mercosul) é a união aduaneira de cinco países da América do Sul. Inicialmente composto por Argentina, Brasil, Paraguai e Uruguai, o objetivo primordial do Tratado de Assunção (denominação dada ao tratado para a criação do Mercosul) é a integração dos quatro Estados partícipes:

[...] por meio da livre circulação de bens, serviços e fatores produtivos, do estabelecimento de uma Tarifa Externa Comum (TEC), da adoção de uma política comercial comum, da coordenação de políticas macroeconômicas e setoriais, e da harmonização de legislações nas áreas pertinentes. Em dezembro de 1994, foi aprovado o Protocolo de Ouro Preto, que estabelece a estrutura institucional do MERCOSUL e o dota de personalidade jurídica internacional. (ITAMARTY, 2014, $\mathrm{s} / \mathrm{p})$.

A partir de 31 de julho de 2012 o bloco passou a contar com a presença de um quinto membro, a Venezuela, país este que só pôde ser incluído devido à suspenção temporária do Paraguai, já que este vetava a inclusão dela no bloco.

O Mercosul trata de várias questões como social, política, educacional, científica. Aborda questões relativas ao comércio, mas também se preocupa com tudo aquilo que se relaciona com o bem-estar dos cidadãos como a educação, a proteção do meio ambiente, melhoramento das passagens de fronteira, a saúde, etc. (MERCOSUL, 2014). A aliança feita entre esses países é uma forma de se fortalecerem juntamente em prol do benefício de todas as nações envolvidas.

Há, no âmbito do bloco, uma preocupação com a "[...] a necessidade de promover o desenvolvimento científico e tecnológico dos estados partes [...]” (RECyT) para ampliar a 
oferta e a qualidade dos bens e serviços disponíveis, a fim de melhorar as condições de vida de seus habitantes. O RECyT (Reunião Especializada em Ciência e Tecnologia) tem como objetivo central a promoção do desenvolvimento científico e tecnológico dos países membros do Mercosul. No plano regional, um dos principais campos do RECyT é a promoção e o incentivo da pesquisa em todos os níveis, buscando contribuir para o processo de integração regional (MERCOSUR, 2014).

Portanto, o turismo não foi identificado como uma área de interesse de desenvolvimento. Segundo Tomazzoni, Patrucco e Buhler (2014), o Tratado de Assunção estabeleceu, para a constituição do Mercosul, no Anexo V, dez subgrupos de trabalho para a coordenação das políticas macroeconômicas e setoriais, mas o turismo não foi contemplado como um grupo específico de trabalho, provavelmente por não ser considerado um dos setores prioritários das políticas macroeconômicas do Mercosul.

E é o que este trabalho visa ressaltar, na tentativa de incorporar o turismo como atividade motivadora para o desenvolvimento dos Estados partes, a produção do conhecimento em turismo é uma eficiente maneira de promover a atividade e colher seus frutos.

Essas interações entre os países, no âmbito do turismo, podem ser viabilizadas (ou iniciadas) por meio da produção de conhecimento em turismo, através dos CPT, que por sua vez poderiam ser compreendida a partir das relações de parcerias e redes e da sua produção conjunta.

Assim, a partir da coleta de dados dos países do Mercosul foi possível fazer uma análise das possíveis interações entre os centros de pesquisa em turismo. $\mathrm{O}$ retrato dos cinco países representantes pôde ser observado nas considerações abaixo.

\subsection{OBJETO DE ESTUDO: OS CPT DE CADA PAÍS E SUAS INTERRELAÇÕES}

\subsubsection{ARGENTINA}

$\mathrm{Na}$ Argentina foram encontrados, no total, 130 instituições de ensino superior, entre públicas $(50,77 \%)$ e privadas $(49,23 \%)$. Através da análise das informações disponíveis de cada uma delas, observou-se que do total de IES identificadas, 60 (44,15\% das instituições do país) ofertavam algum tipo de curso ou formação em turismo. Especificamente 105 (81\%) são da categoria universidade 25 (19\%) é da categoria não-universidade. 
Dessas 60 IES que ofertavam algum tipo de curso ou formação em turismo foi possível identificar a existência de 9 centros de pesquisa, com temáticas variadas, os quais estavam concentrados em 7 (8,14\% da amostra de) instituições distintas.

Os 7 centros de pesquisa são especificamente dedicados ao estudo do turismo. A distribuição dos CPT conforme as áreas temáticas, a IES vinculada e o tipo pode ser observado no quadro 1.

Quadro 1 Identificação dos centros de pesquisa na Argentina

\begin{tabular}{|c|c|c|c|}
\hline Instituição & Nome & Tipo & $\begin{array}{c}\text { Área } \\
\text { Temática }\end{array}$ \\
\hline $\begin{array}{l}\text { Universidad Nacional de } \\
\text { General San Martín }\end{array}$ & $\begin{array}{l}\text { Centro de Investigación y } \\
\text { Desarrollo del } \\
\text { Turismo (CIDeTur-EEyN) }\end{array}$ & Observatório & $\begin{array}{l}\text { Economia e } \\
\text { Gestão }\end{array}$ \\
\hline $\begin{array}{l}\text { Universidad Nacional de la } \\
\text { Patagonia San Juan Bosco }\end{array}$ & $\begin{array}{l}\text { Observatorio de Economía y } \\
\text { Administración del Turismo } \\
\text { (OBSECATUR - GETACE) }\end{array}$ & Observatório & $\begin{array}{l}\text { Economia e } \\
\text { Gestão }\end{array}$ \\
\hline $\begin{array}{l}\text { Universidad de la Cuenca del } \\
\text { Plata }\end{array}$ & $\begin{array}{l}\text { Observatorio Económico y } \\
\text { Social }\end{array}$ & Observatório & $\begin{array}{l}\text { Economia e } \\
\text { Gestão }\end{array}$ \\
\hline Universidad Nacional de Lanús & $\begin{array}{l}\text { Observatorio Turistico de } \\
\text { Argentina (Observatur) }\end{array}$ & Observatório & $\begin{array}{l}\text { Economia e } \\
\text { Gestão }\end{array}$ \\
\hline Universidade de Comahue & $\begin{array}{c}\text { Centro de Estudio del } \\
\text { Conocimiento e Innovación } \\
\text { Empresarial Turístico } \\
(\text { CECIET })\end{array}$ & $\begin{array}{l}\text { Centro de } \\
\text { pesquisa }\end{array}$ & $\begin{array}{l}\text { Economia e } \\
\text { Gestão }\end{array}$ \\
\hline Universidad Nacional de Lanús & $\begin{array}{l}\text { Centro Internacional de } \\
\text { Estudios sobre Turismo y } \\
\text { Desarrollo (CIETyD) }\end{array}$ & $\begin{array}{c}\text { Centro de } \\
\text { pesquisa }\end{array}$ & $\begin{array}{l}\text { Planejamento } \\
\text { Turístico }\end{array}$ \\
\hline $\begin{array}{l}\text { Universidad Nacional del } \\
\text { Comahue }\end{array}$ & $\begin{array}{c}\text { Centro de Estudios para la } \\
\text { Planificación y el Desarrollo } \\
\text { Turístico Sustentable - } \\
\text { CEPLADES }\end{array}$ & $\begin{array}{l}\text { Centro de } \\
\text { pesquisa }\end{array}$ & $\begin{array}{l}\text { Planejamento } \\
\text { Turístico }\end{array}$ \\
\hline $\begin{array}{c}\text { Universidad Nacional de Mar } \\
\text { del Plata }\end{array}$ & $\begin{array}{c}\text { Centro de Investigaciones } \\
\text { Turísticas }\end{array}$ & $\begin{array}{l}\text { Centro de } \\
\text { pesquisa }\end{array}$ & Turismo Geral \\
\hline Universidad Nacional de la Plata & $\begin{array}{l}\text { Instituto de Investigaciones } \\
\text { en Turismo }\end{array}$ & Instituto & Turismo Geral \\
\hline
\end{tabular}

Fonte: Elaboração própria a partir dos dados da pesquisa.

\subsubsection{BRASIL}

No Brasil foram encontrados, no total, 2407 instituições de ensino superior, entre públicas $(6,36 \%)$ e privadas $(93,64 \%)$. Através da análise das informações disponíveis de cada uma delas, observou-se a existência de 347 IES que ofertavam algum tipo de curso ou formação em turismo (cerca de $14,41 \%$ das instituições identificadas neste país). 
Dessas 347 IES que ofertavam algum tipo de curso ou formação em turismo foi possível identificar a existência de 57 centros de pesquisa, com temáticas variadas.

Desses 57 centros de pesquisa. A distribuição dos CPT conforme as áreas temáticas, a IES vinculada e o tipo pode ser observado no quadro 3.

\subsubsection{PARAGUAI}

No Paraguai foram encontrados, no total, 65 instituições de ensino superior, entre públicas $(12,31 \%)$ e privadas $(87,69 \%)$. Através da análise das informações disponíveis de cada uma delas, observou-se que 18 IES (26,86\% das universidades daquele país) ofertavam algum tipo de curso ou formação em turismo.

Dessas 18 universidades que ofertavam algum tipo de curso ou formação em turismo não foram encontrados nenhum centro de pesquisa.

\subsubsection{URUGUAI}

No Uruguai foram encontrados, no total, 37 instituições de ensino superior, entre públicas $(13,51 \%)$ e privadas $(86,49 \%)$. Através da análise das informações disponíveis de cada uma delas, observou-se que das 37 IES, 13 ofertavam algum tipo de curso ou formação em turismo, o que representa cerca de $35,13 \%$ das instituições de ensino superior daquele país.

Dessas 13 universidades que ofertavam algum tipo de curso ou formação em turismo foi possível identificar a existência de 1 centro de pesquisa, que se concentra na área de economia e gestão, sendo o único centro de pesquisa vinculado a uma das 13 universidades com curso de turismo encontrados (quadro 2).

Quadro 2 Identificação dos centros de pesquisa no Uruguai

\begin{tabular}{|l|l|l|l|}
\hline \multicolumn{1}{|c|}{ Instituição } & \multicolumn{1}{|c|}{ Nome } & \multicolumn{1}{c|}{ Tipo } & \multicolumn{1}{c|}{ Área temática } \\
\hline $\begin{array}{l}\text { Universidad Catolica } \\
\begin{array}{l}\text { Del Uruguay “Damaso } \\
\text { Antonio Larrañaga" }\end{array}\end{array}$ & $\begin{array}{l}\text { Centro de Investigación } \\
\text { en Marketing y y y } \\
\text { Turismo (CIMYT) }\end{array}$ & $\begin{array}{l}\text { Centro de } \\
\text { Pesquisa }\end{array}$ & $\begin{array}{l}\text { Economia e } \\
\text { Gestão }\end{array}$ \\
\hline
\end{tabular}

Fonte: Elaboração própria a partir dos dados da pesquisa. 
Quadro 3 Identificação dos Centros de Pesqusia no Brasil

\begin{tabular}{|c|c|c|c|}
\hline Instituição & Nome & Tipo & Área Temática \\
\hline Universidade Federal de Juiz de Fora & COGITO - Conhecimento, Gestão e Turismo & $\begin{array}{l}\text { Grupo de pesquisa } \\
\end{array}$ & Ciências Sociais \\
\hline Universidade Federal de Juiz de Fora & $\begin{array}{c}\text { Observatório Econômico e Social do Turismo } \\
\text { (OEST) }\end{array}$ & Observatório & Ciências Sociais \\
\hline $\begin{array}{c}\text { Universidade Federal do Rio Grande do } \\
\text { Norte }\end{array}$ & $\begin{array}{l}\text { ESCRITUR - Estudos Críticos em Turismo } \\
\end{array}$ & Grupo de pesquisa & Ciências Sociais \\
\hline Universidade Federal do Rio de Janeiro & Turismo, Ciências Sociais e Patrimônio & Grupo de pesquisa & Ciências Sociais \\
\hline Universidade Federal do Rio de Janeiro & Grupo de Estudos em Turismo e Sociedade & Grupo de pesquisa & Ciências Sociais \\
\hline Universidade Federal Fluminense & T-Cult Turismo, Cultura e Sociedade - UFF & Grupo de pesquisa & Ciências Sociais \\
\hline Universidade Federal do Paraná & Turismo e Sociedade & Grupo de pesquisa & Ciências Sociais \\
\hline Universidade do Vale do Itajaí & TES - Turismo, Espaço e Sociedade & Grupo de pesquisa & Ciências Sociais \\
\hline $\begin{array}{l}\text { Universidade do Estado do Rio Grande } \\
\text { do Norte }\end{array}$ & $\begin{array}{c}\text { Gestão Organizacional e Pesquisa Quantitativa em } \\
\text { Turismo - GOPQTu }\end{array}$ & Grupo de pesquisa & $\begin{array}{c}\text { Economia e } \\
\text { Gestão }\end{array}$ \\
\hline $\begin{array}{c}\begin{array}{c}\text { Universidade Federal do Rio Grande do } \\
\text { Norte }\end{array} \\
\text {. }\end{array}$ & $\begin{array}{l}\text { Grupo de Estudos em Gestão do Turismo } \\
\text { (GESTUR) }\end{array}$ & Grupo de pesquisa & Ciências Sociais \\
\hline Universidade Federal de São Carlos & $\begin{array}{c}\text { Observatório do Turismo do Estado de São Paulo } \\
\text { (OTURESP) }\end{array}$ & Observatório & $\begin{array}{c}\text { Economia e } \\
\text { Gestão }\end{array}$ \\
\hline $\begin{array}{l}\text { Universidade Federal do Estado do Rio } \\
\text { de Janeiro }\end{array}$ & $\begin{array}{l}\text { Gestão Empresarial, Turismo e Desenvolvimento } \\
\text { Sustentável }\end{array}$ & Grupo de pesquisa & Ciências Sociais \\
\hline Universidade Federal Fluminense & Observatório do Turismo do Rio de Janeiro & Observatório & $\begin{array}{c}\text { Economia e } \\
\text { Gestão }\end{array}$ \\
\hline $\begin{array}{l}\text { Instituto Federal de Educação, Ciência e } \\
\text { Tecnologia de Santa Catarina }\end{array}$ & $\begin{array}{c}\text { GPGTUR - Grupo de Pesquisa em Gestão do } \\
\text { Turismo }\end{array}$ & Grupo de pesquisa & $\begin{array}{l}\text { Economia e } \\
\text { Gestão }\end{array}$ \\
\hline Universidade Anhembi Morumbi & $\begin{array}{l}\text { Núcleo de Pesquisa - Escola de Negócios e } \\
\text { Hospitalidade (área temática de pesquisa em } \\
\text { Serviços e Organizaçôes) }\end{array}$ & Centro de pesquisa & Ciências Sociais \\
\hline Universidade de São Paulo & $\begin{array}{l}\text { Pesquisa, Educação e Atuaç̃o Profissional em } \\
\text { Turismo e Hospitalidade }\end{array}$ & Grupo de pesquisa & Educação \\
\hline $\begin{array}{l}\text { Instituto Federal de Educação, Ciência e } \\
\text { Tecnologia do Rio Grande do Norte }\end{array}$ & Hospitalidade, Turismo e Educação Profissional & Grupo de pesquisa & Educação \\
\hline $\begin{array}{l}\text { Instituto Federal de Educacăão, Ciência e } \\
\text { Tecnologia do Rio Grande do Sul }\end{array}$ & GECIT - Educação, cidadania e turismo & $\begin{array}{l}\text { Grupo de pesquisa } \\
\end{array}$ & Educação \\
\hline Universidade Caxias do Sul & $\begin{array}{l}\text { Turismo: Desenvolvimento Humano e Social, } \\
\text { Linguagem e Processos Educacionais }\end{array}$ & Grupo de pesquisa & Educação \\
\hline $\begin{array}{l}\text { Universidade do Estado do Rio Grande } \\
\text { do Norte }\end{array}$ & $\begin{array}{l}\text { Grupo de Pesquisas em Lazer, Turismo e Trabalho } \\
\text {-GEPLAT/UERN }\end{array}$ & Grupo de pesquisa & $\begin{array}{c}\text { Entretenimento/La } \\
\text { zer }\end{array}$ \\
\hline Universidade de São Paulo & Cultura e Arte no Lazer e Turismo & $\begin{array}{l}\text { Grupo de pesquisa } \\
\end{array}$ & $\begin{array}{c}\begin{array}{c}\text { Entretenimento/La } \\
\text { zer }\end{array} \\
0\end{array}$ \\
\hline $\begin{array}{l}\text { Instituto Federal de Educação, Ciência e } \\
\text { Tecnologia do Ceará }\end{array}$ & Grupo de Estudo de Geografia, História e Turismo & Grupo de pesquisa & Geografia \\
\hline Universidade Federal Fluminense & TGTur - Turismo: Gestão e Territórios & Grupo de pesquisa & Geografia \\
\hline $\begin{array}{l}\text { Instituto Federal de Educação, Ciência e } \\
\text { Tecnologia de Brasilia }\end{array}$ & $\begin{array}{l}\text { Núcleo de Pesquisa em Turismo e Hospitalidade } \\
\text { do IFB }\end{array}$ & Grupo de pesquisa & Hospitalidade \\
\hline $\begin{array}{l}\text { Instituto Federal de Educacãoo, Ciência e } \\
\text { Tecnologia do Ceará }\end{array}$ & $\begin{array}{l}\text { Gestão do Turismo e da Hospitalidade nos } \\
\text { Territórios }\end{array}$ & Grupo de pesquisa & Hospitalidade \\
\hline Universidade Anhembi Morumbi & $\begin{array}{l}\text { Núcleo de Pesquisa Hospitalidade (área temática } \\
\text { de pesquisa em Processos e Práticas) }\end{array}$ & $\begin{array}{l}\text { Centro de pesquisa } \\
\end{array}$ & Hospitalidade \\
\hline $\begin{array}{l}\text { Instituto Federal de Educação, Ciência e } \\
\text { Tecnologia do Ceará }\end{array}$ & $\begin{array}{l}\text { ICTA - Identidades Culturais, Turismo e } \\
\text { Alimentos }\end{array}$ & Grupo de pesquisa & $\begin{array}{c}\text { Patrimônio } \\
\text { Cultural }\end{array}$ \\
\hline Universidade Estadual do Ceará & $\begin{array}{l}\text { Gestão Integrada da Zona Costeira } \\
\end{array}$ & Grupo de pesquisa & $\begin{array}{l}\text { Planejamento } \\
\text { Turístico }\end{array}$ \\
\hline $\begin{array}{l}\text { Universidade do Estado do Rio Grande } \\
\text { do Norte }\end{array}$ & $\begin{array}{l}\text { Gestão e planejamento Sustentável do Turismo } \\
\end{array}$ & Grupo de pesquisa & $\begin{array}{c}\text { Planejamento } \\
\text { Turistico }\end{array}$ \\
\hline
\end{tabular}

\begin{tabular}{|c|c|c|c|}
\hline Instituição & Nome & Tipo & Área Temática \\
\hline $\begin{array}{l}\text { Universidade Federal do Rio Grande do } \\
\text { Norte }\end{array}$ & $\begin{array}{l}\text { Gestão, Turismo e Politicas Públicas - } \\
\text { GEPOLISTUR }\end{array}$ & $\begin{array}{l}\text { Grupo de pesquisa } \\
\end{array}$ & $\begin{array}{c}\text { Planejamento } \\
\text { Turístico }\end{array}$ \\
\hline Universidade Federal da Paraíba & Desenvolvimento, planejamento e turismo & Grupo de pesquisa & $\begin{array}{l}\text { Planejamento } \\
\text { Turístico }\end{array}$ \\
\hline $\begin{array}{l}\text { Instituto Federal de Educação, Ciência e } \\
\text { Tecnologia do Pernambuco }\end{array}$ & Políticas Públicas do Turismo & Grupo de pesquisa & $\begin{array}{l}\text { Planejamento } \\
\text { Turístico }\end{array}$ \\
\hline $\begin{array}{l}\text { Universidade Federal do Rio Grande do } \\
\text { Norte }\end{array}$ & $\begin{array}{l}\text { Grupo de Pesquisa em Planejamento e } \\
\text { Organização do Turismo - GEPPOT }\end{array}$ & Grupo de pesquisa & $\begin{array}{c}\text { Planejamento } \\
\text { Turístico }\end{array}$ \\
\hline $\begin{array}{l}\text { Universidade de São Paulo } \\
\end{array}$ & $\begin{array}{c}\text { Teorização do Planejamento Territorial do } \\
\text { Turismo }\end{array}$ & Grupo de pesquisa & $\begin{array}{l}\text { Planejamento } \\
\text { Turístico }\end{array}$ \\
\hline Universidade do Vale do Itajaí & $\begin{array}{c}\text { PLAGET - Planejamento e Gestão do Espaço } \\
\text { Turístico }\end{array}$ & Grupo de pesquisa & $\begin{array}{l}\text { Planejamento } \\
\text { Turístico }\end{array}$ \\
\hline Universidade de Brasília & Observatórios para o turismo sustentável & Observatório & Recursos naturais \\
\hline Universidade Estadual de Roraima & $\begin{array}{l}\text { Laboratário de Turismo, Ecologia e Meio } \\
\text { Ambiente da Universidade Estadual de Roraima } \\
\text { (LabTEMA) }\end{array}$ & Grupo de pesquisa & Recursos naturais \\
\hline $\begin{array}{l}\text { Universidade Federal dos Vale do } \\
\text { Jequitinhonha e Mucuri }\end{array}$ & Destinos Turísticos e Sustentabilidade & Grupo de pesquisa & Recursos naturais \\
\hline Universidade Federal Fluminense & $\begin{array}{c}\text { Turismo, Meio Ambiente Urbano e Inclusão Social } \\
\text { - TURis }\end{array}$ & Grupo de pesquisa & Recursos naturais \\
\hline Universidade Federal do Paraná & $\begin{array}{c}\text { Planejamento, Gestão e Controle do } \\
\text { Desenvolvimento Sustentavel do Turismo } \\
\end{array}$ & Grupo de pesquisa & Recursos naturais \\
\hline Universidade do Vale do Itajaí & $\begin{array}{l}\text { HOGAST- Grupo de Pesquisa Hotelaria, } \\
\text { Gastronomia Serviços Turisticos }\end{array}$ & Grupo de pesquisa & $\begin{array}{c}\text { Serviços } \\
\text { Turísticos } \\
\end{array}$ \\
\hline Universidade de Brasilia & Centro de Excelência em Turismo (CET) & Centro de pesquisa & Turismo Geral \\
\hline $\begin{array}{l}\text { Centro Federal de Educacão Tecnológica } \\
\text { Suckow da Fonseca }\end{array}$ & Laboratório de Turismo & Laboratótio & Turismo Geral \\
\hline $\begin{array}{l}\text { Fundação Universidade Federal do } \\
\text { Pampa }\end{array}$ & Laboratório de Turismo - Labortur & Laboratório & Turismo Geral \\
\hline Universidade Federal de Pelotas & Laboratório de pesquisa & Laboratótio & Turismo Geral \\
\hline $\begin{array}{l}\text { Faculdade Educacional de Cornélio } \\
\text { Procópio }\end{array}$ & Núcleo de Planejamento Turístico & Centro de pesquisa & Turismo Geral \\
\hline $\begin{array}{l}\text { Pontifica Universidade Católica Paraná } \\
\end{array}$ & Núcleo de Estudos e Pesquisas em Turismo & Centro de pesquisa & Turismo Geral \\
\hline Universidade Estadual do Piauí & $\begin{array}{l}\text { NETUR - Núcleo de Estudos, Pesquisas e Projetos } \\
\text { em Turismo }\end{array}$ & Grupo de pesquisa & Outros \\
\hline Universidade de São Paulo & $\begin{array}{l}\text { Avaliação Pedagógica Permanente em Relaçōes } \\
\text { Públicas, Propaganda e Turismo }\end{array}$ & $\begin{array}{l}\text { Grupo de pesquisa } \\
\end{array}$ & Outros \\
\hline Universidade Federal de Alagoas & $\begin{array}{c}\text { Observatório Transdisciplinar de Pesquisas em } \\
\text { Turismo }\end{array}$ & Grupo de pesquisa & Outros \\
\hline Universidade de São Paulo & $\begin{array}{l}\text { Turismo Internacional } \\
\end{array}$ & Grupo de pesquisa & Outros \\
\hline Universidade Federal do Rio de Janeiro & $\begin{array}{l}\text { INTERTUR - Pesquisas Interdisciplinares em } \\
\text { Turismo e Cidades }\end{array}$ & Grupo de pesquisa & Outros \\
\hline Universidade Federal do Rio de Janeiro & $\begin{array}{l}\text { Turismo, Direito e Desenvolvimento } \\
\end{array}$ & Grupo de pesquisa & Outros \\
\hline Universidade Federal do Rio de Janeiro & Grupo Transportes e o Turismo & Grupo de pesquisa & Outros \\
\hline Universidade Federal do Rio de Janeiro & Grupo de Pesquisa Espaço, Imagem e Turismo & Grupo de pesquisa & Outros \\
\hline Universidade Federal Fluminense & Histur - Laboratório de História do Turismo & Grupo de pesquisa & Outros \\
\hline Universidade Federal do Paraná & $\begin{array}{l}\text { Turismo, Tecnologia, Informação, Comunicação e } \\
\text { Conhecimento - TURITEC }\end{array}$ & Grupo de pesquisa & Outros \\
\hline
\end{tabular}




\subsubsection{VENEZUELA}

$\mathrm{Na}$ Venezuela foram encontrados, no total, 174 instituições de ensino superior, entre públicas $(47,13 \%)$ e privadas $(52,87 \%)$. Através da análise das informações disponíveis de cada uma delas, observou-se que das 174 IES identificadas 49 (28,16\% das IES daquele país) ofertavam algum tipo de curso ou formação em turismo.

Dessas 49 IES que ofertavam algum tipo de curso ou formação em turismo foi possível identificar a existência de 1 centro de pesquisa, representado 2,04\% das IES que possuem curso superior em turismo (quadro 4).

Quadro 4 Identificação dos centros de pesquisa na Venezuela

\begin{tabular}{|c|c|c|c|}
\hline Instituição & Nome & Tipo & Área temática \\
\hline $\begin{array}{c}\text { Colegio Universitario "Hotel Escuela } \\
\text { de los Andes Venezolanos" }\end{array}$ & $\begin{array}{c}\text { CENINTUR - Centro Nacional } \\
\text { de Investigaciones Turísticas }\end{array}$ & $\begin{array}{c}\text { Centro de } \\
\text { Pesquisa }\end{array}$ & $\begin{array}{c}\text { Serviços } \\
\text { Turísticos }\end{array}$ \\
\hline
\end{tabular}

Fonte: Elaborado pelos autores a partir dos dados da pesquisa.

\subsubsection{SÍNTESE E DISCUSSÃO}

A tabela 3 sintetiza as categorias, bem como os CPT de cada país.

Tabela 3 Centros de Pesquisa em Turismo nos Países do Mercosul

\begin{tabular}{|l|r|r|r|r|r|r|}
\hline Área temática & Argentina & Brasil & Paraguai & Uruguai & Venezuela & Total \\
\hline Ciências da Saúde & 0 & 0 & 0 & 0 & 0 & $\mathbf{0}$ \\
\hline Ciências Sociais & 0 & 8 & 0 & 0 & 0 & $\mathbf{8}$ \\
\hline Economia e Gestão & 5 & 7 & 0 & 1 & 0 & $\mathbf{1 3}$ \\
\hline Educação (Formação profissional) & 0 & 4 & 0 & 0 & 0 & $\mathbf{4}$ \\
\hline Entretenimento/Lazer & 0 & 2 & 0 & 0 & 0 & $\mathbf{2}$ \\
\hline Esportes & 0 & 0 & 0 & 0 & 0 & $\mathbf{0}$ \\
\hline Eventos & 0 & 0 & 0 & 0 & 0 & $\mathbf{0}$ \\
\hline Gastronomia/Restauração & 0 & 0 & 0 & 0 & 0 & $\mathbf{0}$ \\
\hline Geografia & 0 & 2 & 0 & 0 & 0 & $\mathbf{2}$ \\
\hline Hospitalidade & 0 & 3 & 0 & 0 & 0 & $\mathbf{3}$ \\
\hline Patrimônio Cultural & 0 & 1 & 0 & 0 & 0 & $\mathbf{1}$ \\
\hline Planejamento Turístico & 2 & 8 & 0 & 0 & 0 & $\mathbf{1 0}$ \\
\hline Recursos Naturais (e meio & & & & & & \\
ambiente) & 0 & 5 & 0 & 0 & 0 & $\mathbf{5}$ \\
\hline Serviço Turístico & 0 & 1 & 0 & 0 & 1 & $\mathbf{2}$ \\
\hline Turismo Geral & 2 & 6 & 0 & 0 & 0 & $\mathbf{8}$ \\
\hline Outros & 0 & 10 & 0 & 0 & 0 & $\mathbf{1 0}$ \\
\hline Total & $\mathbf{9}$ & $\mathbf{5 7}$ & $\mathbf{0}$ & $\mathbf{1}$ & $\mathbf{1}$ & $\mathbf{6 8}$ \\
\hline
\end{tabular}

Fonte: Elaborado pelos autores a partir dos dados da pesquisa. 
A partir desses dados foi possível fazer um cruzamento de dados entre os centros de pesquisa do Mercosul. De início, cabe ressaltar a baixa incidência de CPT formais nesses países. O Brasil obteve a maior quantidade, que pode estar relacionado a sua extensão territorial e a quantidade de IES presente.

A figura 1 aponta a distribuição dos CPT de cada país segundo suas ênfases, donde se pode observar certa concentração na área temática de economia e gestão, com 3 centros de pesquisa. E nas áreas temáticas de Turismo Geral, Planejamento Turístico e Serviço Turístico encontra-se 2 centros de pesquisa para cada área.Vale ressaltar que é possível também visualizar uma polarização entre países: enquanto nos demais países do Mercosul há certa homogeneidade em termos dos focos de atuação dos CPT cujas ênfases são predominantemente na área de economia e gestão e planejamento turístico, já no Brasil há uma maior diversificação dos CPT, onde se incluem aqueles na área de ciências sociais e serviço turístico (figura 1).

Figura 1 Ênfases dos Centros de Pesquisa de Turismo

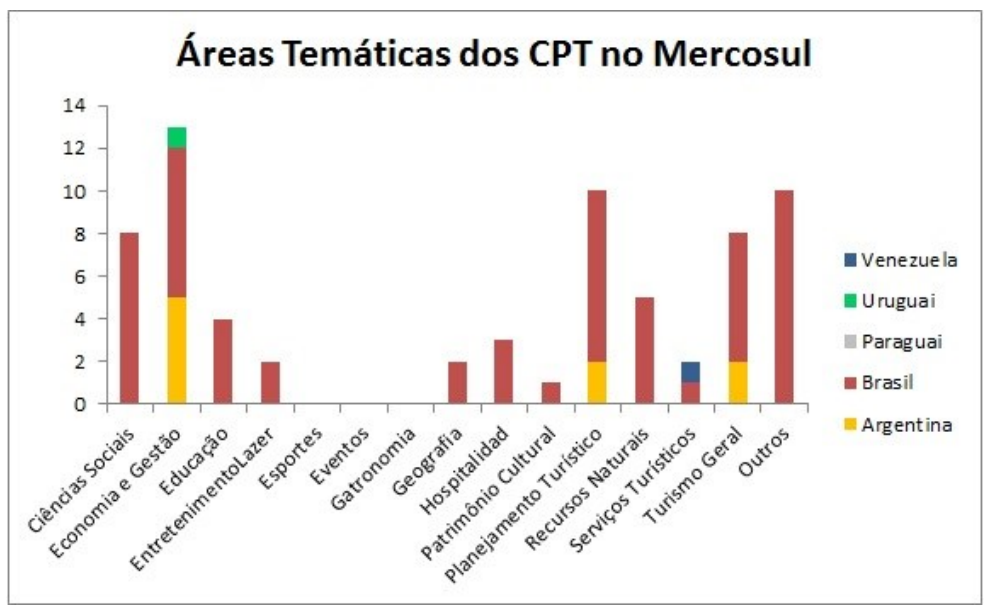

Fonte: Elaborado pelos autores a partir dos dados da pesquisa.

Apesar da identificação e classificação dos centros de pesquisa, com as informações disponíveis em cada um dos sítios eletrônicos das universidades, não se constatou a menção a outro centro de pesquisa por parte de algum nenhum dos CPT analisados. A ausência de informações atualizadas sobre a produção científica dos CPT, bem como a ausência de indicação de formal de relações com outros CPT, sugere um estágio de desenvolvimento e atuação ainda local ou regional, sem ligações internacionais. 
Conforme apontado na revisão de literatura sugere-se que uma aproximação inicial, ainda em caráter informal, pontual e esporádica, mas em nível internacional permitiria com que esses CPT pudessem potencializar a troca de conhecimentos produzidos bem como sua intervenção na realidade, supostamente, fortalecendo o estágio de desenvolvimento turístico no Mercosul.

Figura 2 proposta de modelo de interação entre os CPT dos países do Mercosul.

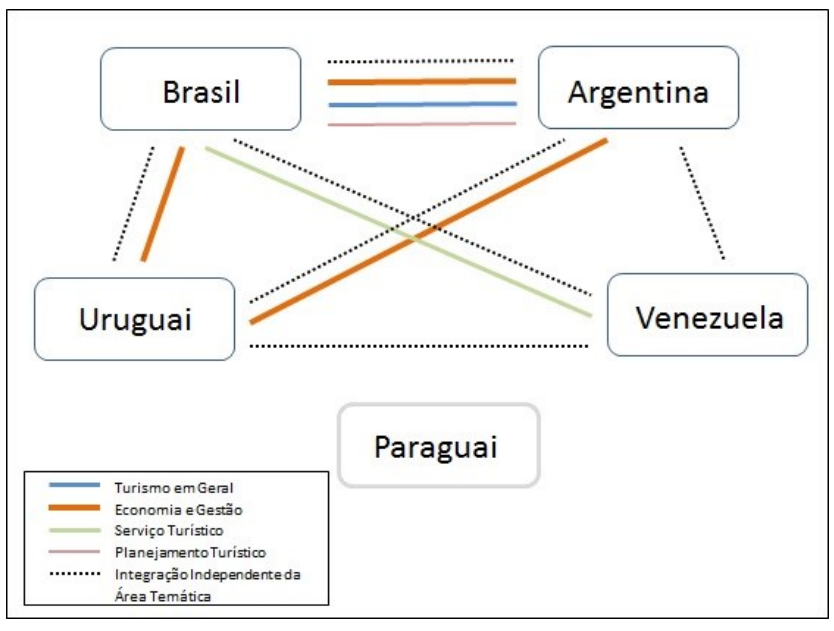

Fonte: Elaborado pelos autores a partir dos dados da pesquisa.

Longe de pretender ser um modelo de análise de redes, este esquema gráfico (representado na Figura 2) apenas ilustra, sugestivamente, as possibilidades de interação a partir dos resultados encontrados, que já poderiam ser iniciadas: 1)Brasil e Argentina na área de Turismo Geral (linha azul); 2)Argentina, Brasil e Uruguai na área de Economia e Gestão (linha laranja); 3)Brasil e Venezuela na área de Serviço Turístico (linha verde); 4) Brasil e Argentina na área de Planejamento Turístico; 5) Integração entre todos os países independente da área temática dos CPT. Ao Paraguai sugere-se a criação de um CPT. Dessa maneira as informações e pesquisas realizadas serão conhecidas por todos os centros de pesquisa, facilitando e acelerando pesquisas e modelos de intervenção

\section{CONSIDERAÇÕES FINAIS}

Retomando o objetivo deste trabalho, que foi mapear os centros de pesquisa em turismo (CPT) existentes nos países do Mercosul, identificar suas ênfases e as possíveis interações entre eles, pode-se concluir que os países do Mercosul apresentam poucos CPT e a 
interação entre eles ainda é quase ausente ou inexistente, não sendo percebida pelas informações institucionais disponíveis em seus sítios eletrônicos.

Os resultados evidenciam uma distribuição assimétrica de CPT entre os países, com ênfase inespecífica ("turismo em geral") e ausência de relações entre si. Existem 81 CPT distribuídos desigualmente, tanto entre ênfases - 12 (14,81\%) deles são generalistas, i.e., sem foco em uma temática específica do turismo - quanto entre os países do Mercosul, onde o Brasil concentra 68 (83,95\%) dos CPT encontrados, enquanto o Paraguai não possui nenhum.

As ênfases de estudos desses centros também são diversas, o que dificulta uma mesma linha de estudo entre eles. Esses poucos centros encontrados também têm poucas relações entre si. Existem parcerias pontuais com outras universidades mas de países fora do Mercosul, como por exemplo a Espanha, e pouco envolvimento dos países que são próximos e que já possuem uma relação quanto ao mesmo bloco econômico. A esse respeito pode-se inferir que o estágio de institucionalização da produção do conhecimento em turismo, como precondição do seu desenvolvimento, ainda é incipiente e local, carecendo de estruturas formais e em escalas nacionais e supranacionais.

Tais elementos parecem ser obstáculos iniciais à aproximação e ao alinhamento entre eles no sentido de desenvolver o turismo na região e consequentemente na América Latina. $\mathrm{O}$ que contribui para a incipiência do setor e os pequenos índices de chegadas de turistas nesses países em relação ao seu potencial. Isso impede que esses países da mesma região, com objetivos comuns produzam conhecimentos específicos de seus interesses em prol de um mesmo objetivo - desenvolver o turismo de uma forma mais saudável e democrática.

A despeito das limitações deste estudo, acredita-se que sua principal contribuição seja lançar luzes ao debate à produção de conhecimentos e pesquisa em turismo de forma institucionalizada, alinhando instâncias de decisão e ação nesse âmbito a fim de se promover uma agenda institucional de pesquisa e o intercâmbio de conhecimentos que poderia levar ao engajamento mútuo com vistas ao desenvolvimento regional. Quando à A integração entre os CPT, um pode contribuir para os estudos dos outros, complementando as lacunas existentes e aproveitando o material já pesquisado, o que proporciona uma melhoria na qualidade e um aumento das discussões em torno do turismo. 


\section{REFERÊNCIAS}

AMARAL, M. I. C. A cooperação entre atores no turismo: Uma perspectiva interorganizacional e intersetorial. In: Revista Turismo \& Desenvolvimento, n:21/22, p.4960. 2014.

CHRISTIAN, L. (s/d). Pesquisa em turismo nos Estados Unidos. Working Paper. Instituto do Transporte, Universidade da Manitoba, EUA.

FREY, L. Brasil: Dilma diz que UE e Mercosul nunca estiveram tão perto de livrecomércio. [Viewed 08 july 2014] Avaiable form: http://dw.de/p/1BEif

GIL, A. C. Métodos e Técnicas de Pesquisa Social. 6ª Ed., São Paulo: Atlas, 2008

GRANOVETTER, M. Economic action and social structure: the problem of embeddedness. American Journal of Sociology. 91(3), 481-510. Chicago. 1985.

KNUPP, M. E. C. G. Análise de Políticas Públicas de Turismo: Uma Abordagem Metodológica Baseada em Redes Sociais. In: Pimentel, T. D.; Emmendoerfer, M. L.;

Tomazzonni, E. L. Gestão Pública do Turismo no Brasil: teorias, metodologias e aplicações. $1^{\text {a }}$ Ed. Caxias do Sul (RS): Editora da Universidade Caxias do Sul / EDUCS, 2014. v.1. 528p. 2014.

LANIADO, R. N., Santos, R. S. dos. A importância do conhecimento e da C\&T para a consolidação das instituições e da democracia. In: Liinc em Revista, v.8, n.1, março, 2012, Rio de Janeiro, p 68-87. Disponível em: < http://www.ibict.br/liinc $>.2012$

MERCOSUL. Disponível em: http://www.mercosul.gov.br/. Acesso em: 24 de março de 2014.

MERCOSUR. Disponível em: http://www.mercosur.int/. Acesso em 24 de março de 2014.

MONTEJANO, J. Estructura del Mercado Turístico. Editora Síntesis. Madrid. 1991.

MTUR. MINISTÉRIO DO TURISMO. Estatísticas Básicas de Turismo (Junho de 2013). Disponível

em: http://www.dadosefatos.turismo.gov.br/dadosefatos/estatisticas_indicadores/estatisticas_basic as_turismo/. Acesso em 27 de março de 2014.

NASSI-CALÒ, L. A ciência na América do Sul na Nature. SciELO em Perspectiva. [viewed 17 May 2016]. Available from: http://blog.scielo.org/blog/2014/07/04/a-ciencia-naamerica-do-sul-na-nature/

OLIVEIRA, G. B. Uma discussão sobre o conceito de desenvolvimento. Revista FAE, 5(2), 41-48. 2002.

OMT - Organização Mundial do Turismo. Disponível em: http://www2.unwto.org/. Acesso em 28 de março em 2014. 
OURIQUES, H. R. (2005). A produção do turismo: fetichismo e dependência. Campinas/SP: Editora Alínea. 2005.

OURIQUES, H. R. (2008). Elementos para uma análise do turismo na economia mundo capitalista. 2008. Disponível em: <http://www.gpepsm.ufsc.br/index_arquivos/OURIQUES HR.pdf>. Acesso em: 22 set. 2011. 2008

PIMENTEL, M. P. C. \& PIMENTEL, T. D. (Org.). Gestão de Destinos Turísticos. $1^{\text {a }}$ Eed. Rio de Janeiro (RJ): Fundação Cecierj / Consórcio Cederj, 2012. v. 1. 288p. 2012.

PIMENTEL, M. P. C.; Pimentel, T. D. El Turismo y los Entornos Sociales: destinos y retos. ARENAS - Revista Sinaloense de Ciencias Sociales, v. 34, p. 117-129, 2013.

SELIN, S. \& CHAVES, D. (1995). Developing an evolutionary tourism partnership model. Annals Tourism Research, 22(4), pp. 884-8856., 1995.

TOMAZZONI, E. L.; PATRUCCO, L. G.; BUHLER, L. V. O Desenvolvimento do turismo no Mercosul. In: Pimentel, T. D.; EMMENDOERFER, M. L.; TOMAZZONNI, E. L. Gestão Pública do Turismo no Brasil: teorias, metodologias e aplicações. $1^{\text {a }}$ Ed. Caxias do Sul (RS): Editora da Universidade Caxias do Sul / EDUCS, 2014. v.1. 528p. 2014

TUOMELA. R. Cooperation as Joint Action. 2010. Disponível em: http://www.analyseund-kritik.net/en/2011-1/AK_Tuomela_2011.pdf. Acesso em 15 jul. 2014.. 2010 